\title{
Thermochemistry of Acetonyl and Related Radicals
}

\author{
Ahmed M. El-Nahas, Joseph W. Bozzelli, John M. Simmie,* \\ Maria V. Navarro, Gráinne Black and Henry J. Curran \\ Environmental Change Institute, \\ National University of Ireland, Galway, Ireland
}

Optimized Structures and Cartesian coordinate of Acetonyl and related radicals at $\mathrm{CBS}-\mathrm{QB3}$

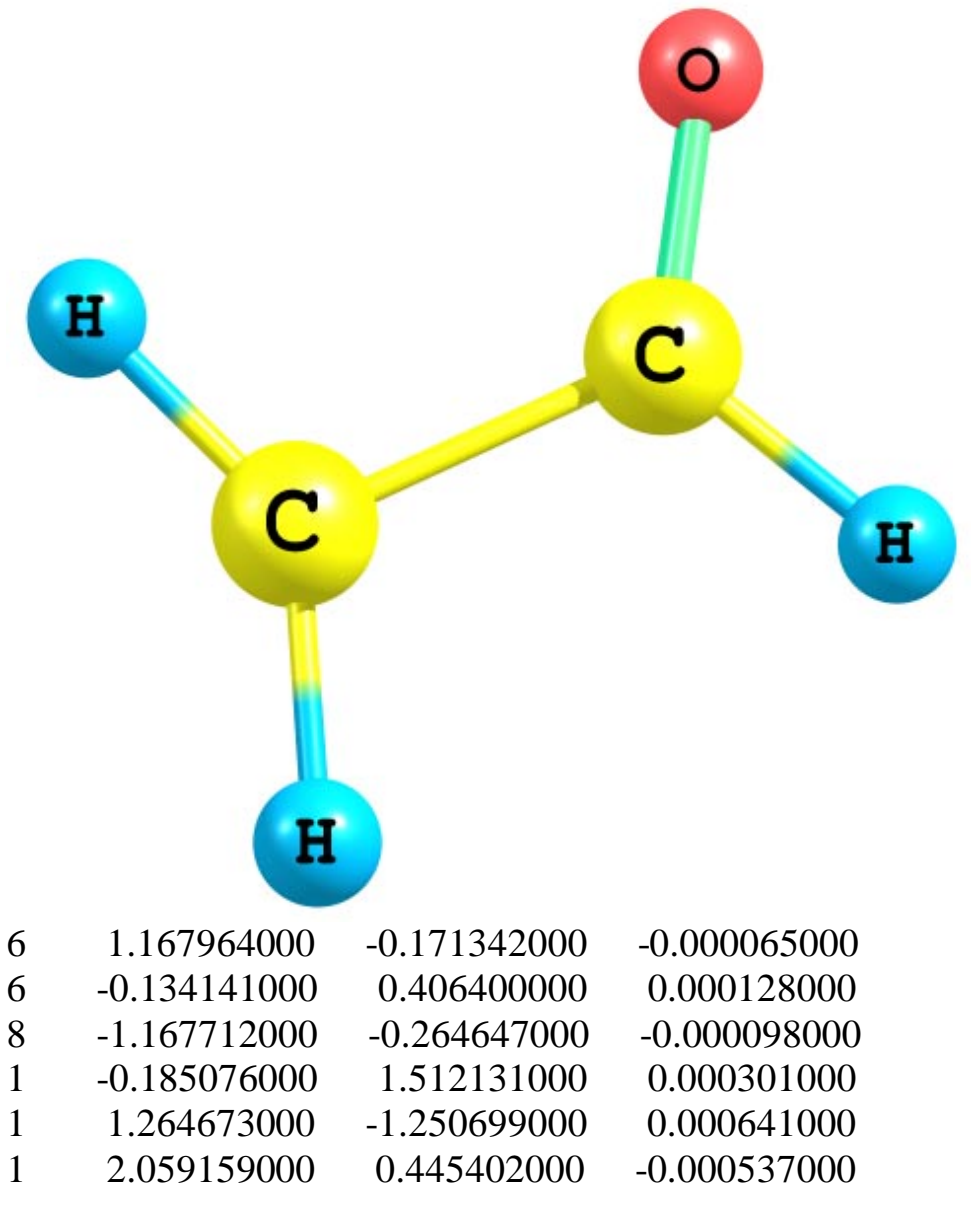

Vibrational frequencies $\left(\mathrm{cm}^{-1}\right)$ :

451.9561

974.9660

1396.8995

2928.5972
505.2191

981.1422

1470.3681

3137.6403
756.3898

1150.6539

1555.3348

3253.4951 


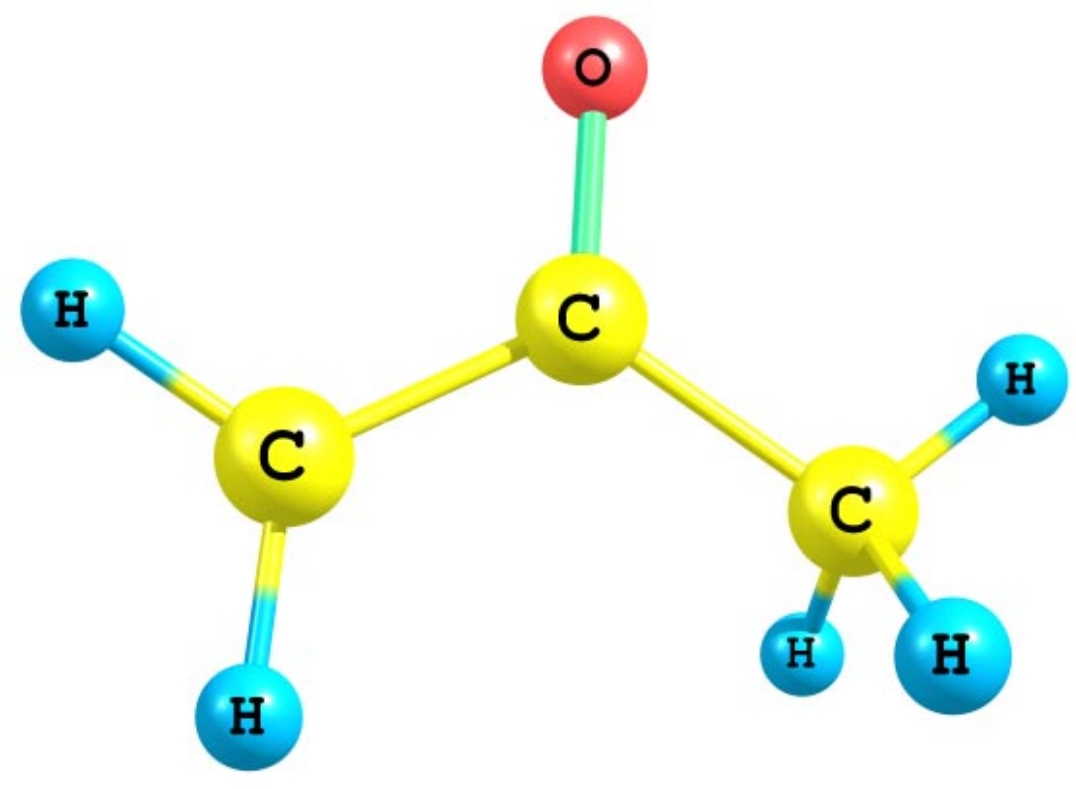

$\begin{array}{rrrr}6 & -1.358903000 & -0.355810000 & -0.000025000 \\ 6 & 0.085852000 & 0.119240000 & -0.000013000 \\ 8 & 0.366689000 & 1.319431000 & -0.000007000 \\ 6 & 1.129681000 & -0.872035000 & -0.000004000 \\ 1 & -2.021258000 & 0.508555000 & -0.002124000 \\ 1 & -1.564283000 & -0.972915000 & -0.880016000 \\ 1 & -1.565222000 & -0.969117000 & 0.882419000 \\ 1 & 2.158636000 & -0.535058000 & 0.000095000 \\ 1 & 0.918835000 & -1.935279000 & -0.000066000\end{array}$

Vibrational frequencies $\left(\mathrm{cm}^{-1}\right)$ :

$\begin{array}{ccc}50.5874 & 364.9956 & 386.0310 \\ 507.7708 & 526.7403 & 750.3779 \\ 814.3581 & 923.6945 & 1025.2335 \\ 1064.6360 & 1264.0291 & 1389.0840 \\ 1455.2980 & 1473.8146 & 1478.9313 \\ 1593.2377 & 3029.8059 & 3085.9553 \\ 3138.3932 & 3140.6105 & 3254.8587\end{array}$




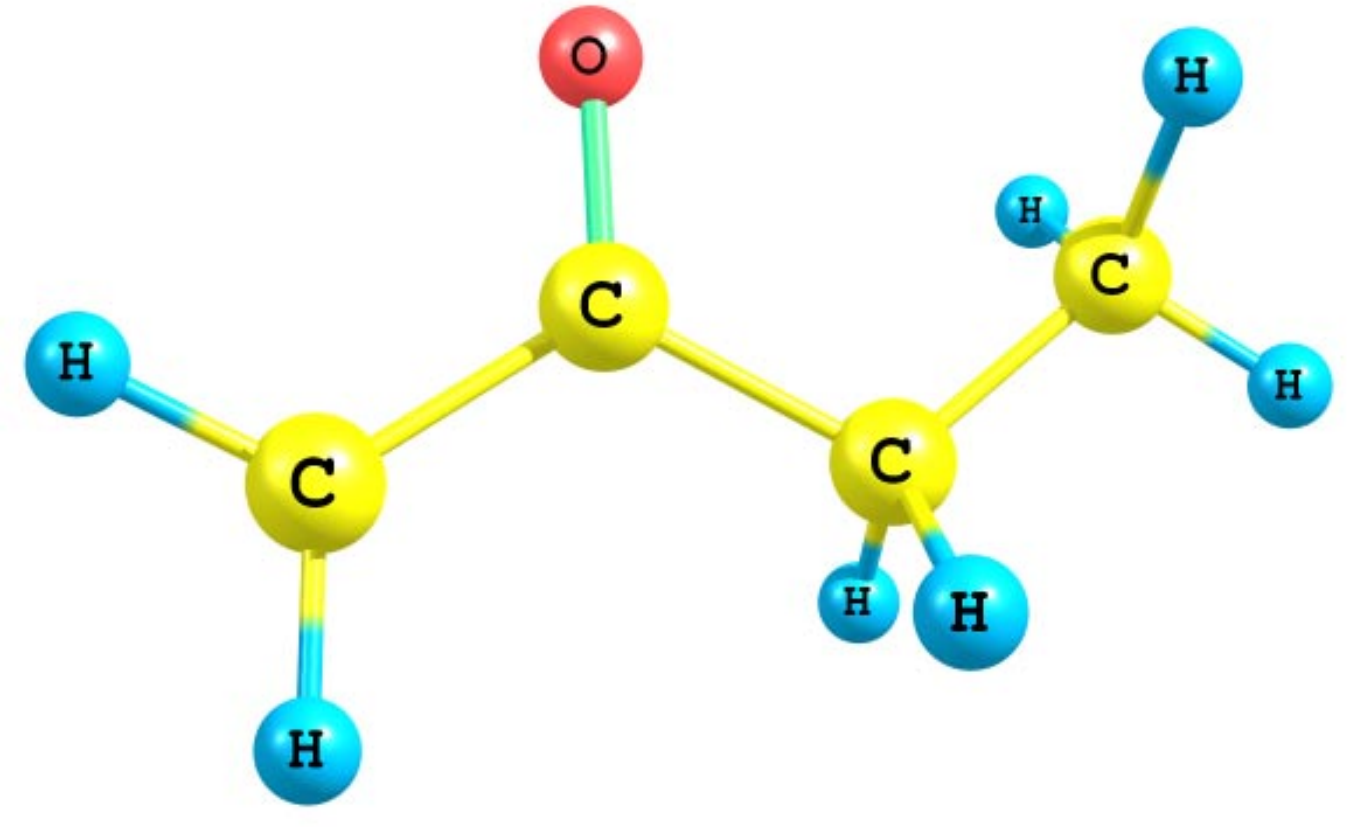

$\begin{array}{rrrr}6 & 1.874199000 & -0.555048000 & -0.000173000 \\ 6 & 0.595006000 & 0.106708000 & -0.000680000 \\ 8 & 0.529138000 & 1.337174000 & 0.000343000 \\ 6 & -0.660701000 & -0.763030000 & 0.000478000 \\ 1 & 1.966010000 & -1.635166000 & -0.000196000 \\ 1 & 2.769571000 & 0.053873000 & 0.000206000 \\ 1 & -0.613257000 & -1.426044000 & 0.873606000 \\ 1 & -0.613491000 & -1.428273000 & -0.870930000 \\ 6 & -1.956520000 & 0.042154000 & -0.000283000 \\ 1 & -2.015271000 & 0.686446000 & -0.879630000 \\ 1 & -2.014548000 & 0.689184000 & 0.877082000 \\ 1 & -2.824023000 & -0.622116000 & 0.001070000\end{array}$

Vibrational frequencies $\left(\mathrm{cm}^{-1}\right)$ :

$\begin{array}{ccc}56.9360 & 191.6435 & 250.0030 \\ 364.1897 & 406.7707 & 496.0751 \\ 587.5171 & 724.4765 & 767.5840 \\ 814.7906 & 975.9353 & 1011.6538 \\ 1077.6418 & 1097.2493 & 1205.3336 \\ 1278.0596 & 1375.0793 & 1417.1354 \\ 1458.6621 & 1462.2461 & 1491.6804 \\ 1501.0302 & 1600.1216 & 3010.2172 \\ 3034.3399 & 3041.4238 & 3106.1890 \\ 3111.3865 & 3137.9490 & 3253.6146\end{array}$




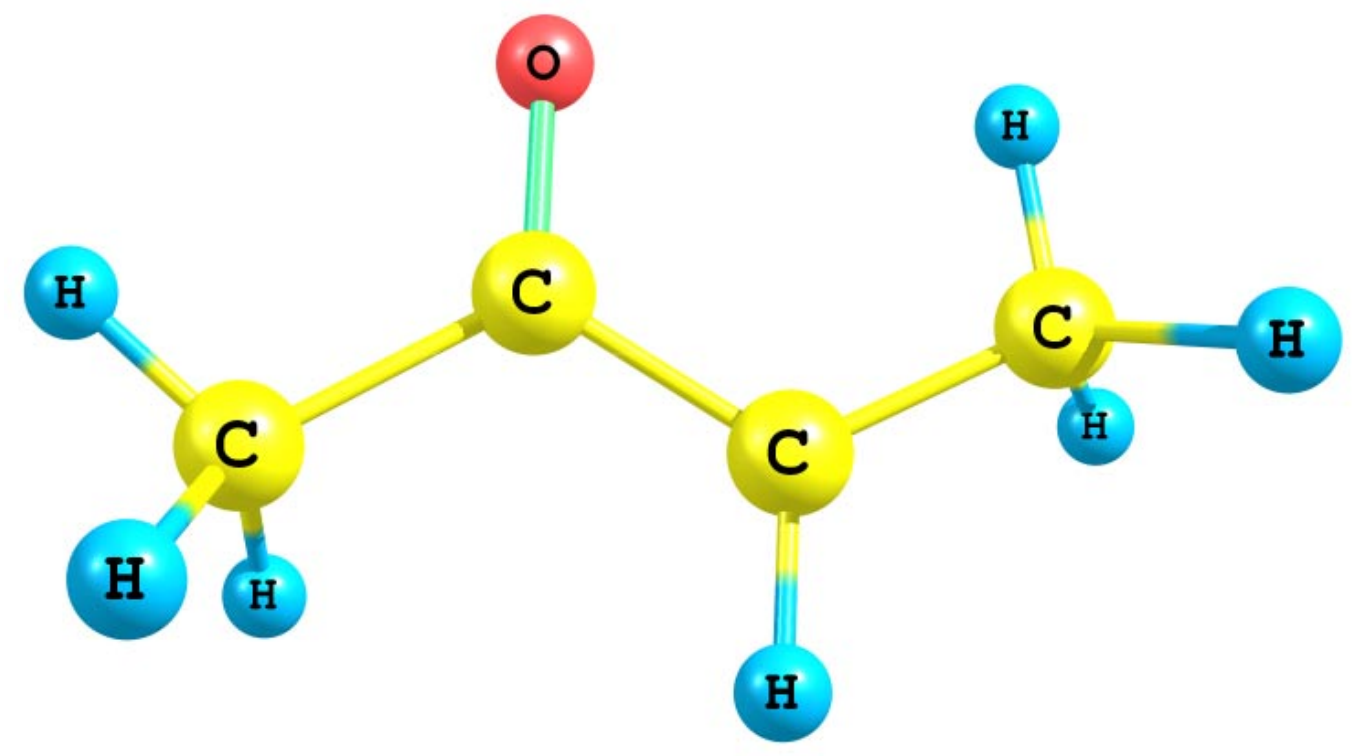

$\begin{array}{rrrr}6 & 1.855224 & -0.558229 & 0.000221 \\ 6 & 0.505592 & 0.143587 & -0.000551 \\ 8 & 0.428305 & 1.374479 & -0.000137 \\ 6 & -0.681788 & -0.679286 & -0.000740 \\ 1 & 2.647697 & 0.188452 & -0.019374 \\ 1 & 1.968227 & -1.181507 & 0.892692 \\ 1 & 1.954232 & -1.214885 & -0.869705 \\ 1 & -0.566643 & -1.759954 & -0.001211 \\ 6 & -2.046118 & -0.098421 & 0.000435 \\ 1 & -2.617265 & -0.432570 & -0.875419 \\ 1 & -1.995015 & 0.990151 & -0.000215 \\ 1 & -2.615144 & -0.431432 & 0.878134\end{array}$

Vibrational frequencies $\left(\mathrm{cm}^{-1}\right)$ :

$\begin{array}{lcc}13.7660 & 107.3749 & 156.2587 \\ 258.4375 & 414.1522 & 523.7526 \\ 599.4726 & 668.0397 & 791.3754 \\ 953.2301 & 978.5821 & 1034.2246 \\ 1041.1488 & 1137.6013 & 1214.5011 \\ 1382.0298 & 1388.9506 & 1420.9420 \\ 1467.5618 & 1475.7320 & 1479.2497 \\ 1486.9829 & 1610.7197 & 2996.2586 \\ 3027.9415 & 3029.3188 & 3083.2610 \\ 3125.4356 & 3139.1523 & 3153.2053\end{array}$




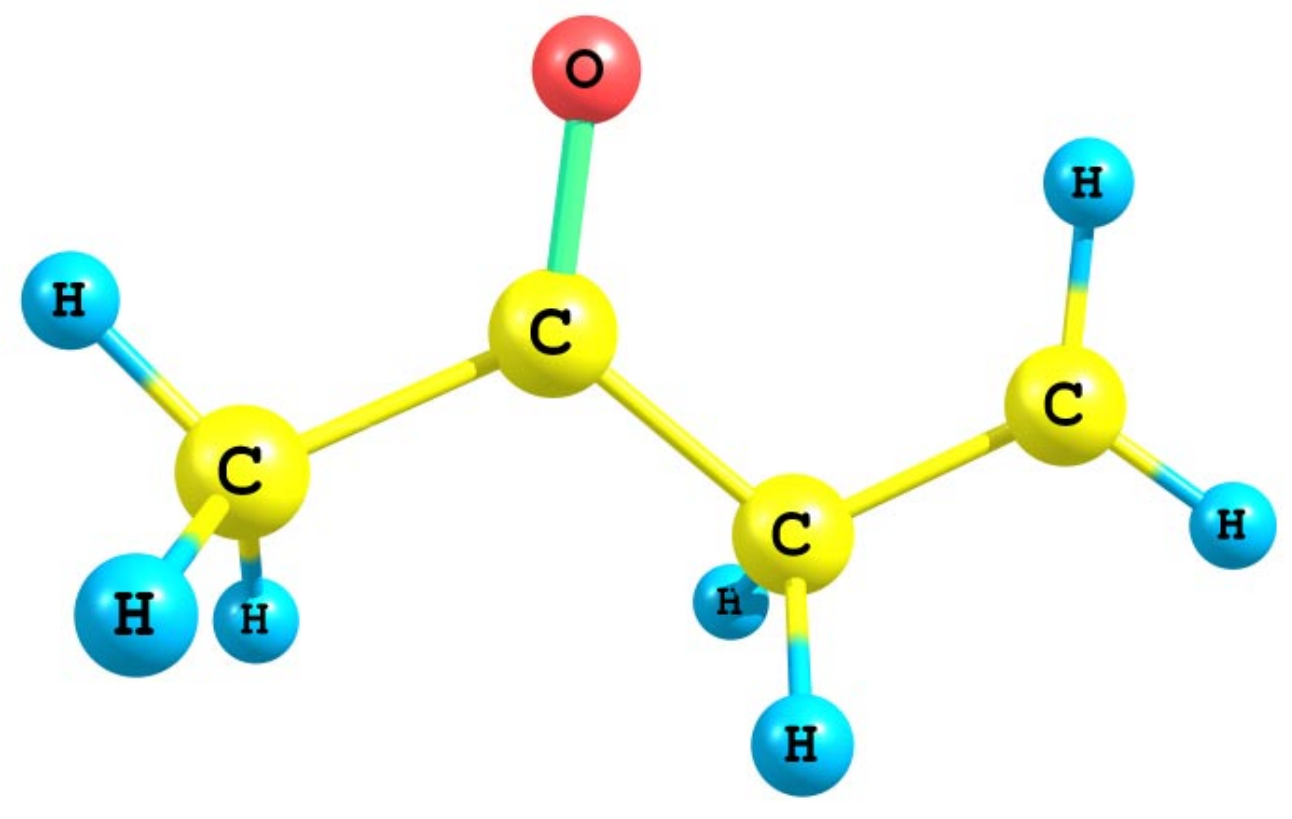

$\begin{array}{rrrr}6 & -1.816207000 & -0.527747000 & 0.045611000 \\ 6 & -0.472706000 & 0.175059000 & -0.019978000 \\ 8 & -0.384078000 & 1.380220000 & -0.027709000 \\ 6 & 0.758147000 & -0.731099000 & -0.072040000 \\ 1 & -1.958406000 & -0.942822000 & 1.049379000 \\ 1 & -2.614471000 & 0.184981000 & -0.157337000 \\ 1 & -1.867095000 & -1.362864000 & -0.658515000 \\ 1 & 0.700204000 & -1.276899000 & -1.031363000 \\ 1 & 0.640004000 & -1.524816000 & 0.681857000 \\ 6 & 2.051482000 & -0.018030000 & 0.069127000 \\ 1 & 2.979569000 & -0.571000000 & 0.126909000 \\ 1 & 2.068529000 & 1.062569000 & 0.074424000\end{array}$

Vibrational frequencies $\left(\mathrm{cm}^{-1}\right)$ :

$\begin{array}{ccc}72.9669 & 110.0934 & 182.3451 \\ 267.8542 & 405.3274 & 432.4177 \\ 489.0485 & 589.2960 & 744.2550 \\ 801.5887 & 943.6188 & 1011.0471 \\ 1022.1887 & 1114.4674 & 1178.8632 \\ 1191.0283 & 1362.4504 & 1386.9595 \\ 1425.0890 & 1437.9403 & 1466.6546 \\ 1479.4945 & 1803.0315 & 2928.6171 \\ 2976.9773 & 3028.6097 & 3086.3878 \\ 3139.5456 & 3154.9605 & 3267.9552\end{array}$




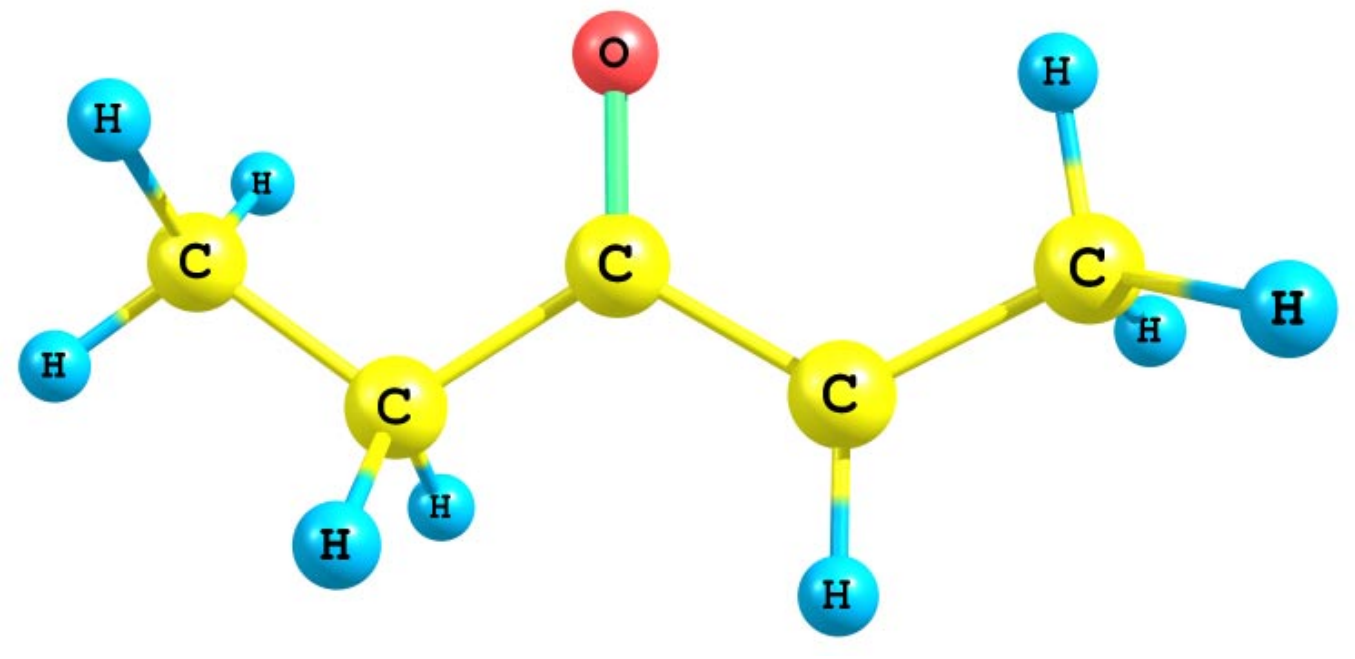

$\begin{array}{rrrr}6 & -1.256957000 & -0.755233000 & -0.000631000 \\ 6 & 0.032825000 & 0.064111000 & -0.000244000 \\ 8 & 0.009520000 & 1.296840000 & -0.000410000 \\ 6 & 1.283354000 & -0.660570000 & 0.000237000 \\ 1 & -1.237588000 & -1.421700000 & 0.870987000 \\ 1 & -1.238111000 & -1.419597000 & -0.873894000 \\ 1 & 1.254294000 & -1.747015000 & 0.000399000 \\ 6 & 2.597373000 & 0.027105000 & 0.000288000 \\ 1 & 2.460369000 & 1.108283000 & 0.000587000 \\ 1 & 3.192284000 & -0.259312000 & -0.876735000 \\ 1 & 3.192561000 & -0.259890000 & 0.876921000 \\ 6 & -2.520111000 & 0.100672000 & 0.000676000 \\ 1 & -2.552574000 & 0.747188000 & 0.879751000 \\ 1 & -2.552809000 & 0.749453000 & -0.876705000 \\ 1 & -3.413489000 & -0.528636000 & 0.000014000\end{array}$

Vibrational frequencies $\left(\mathrm{cm}^{-1}\right)$ :

$\begin{array}{lcc}47.1940 & 110.9569 & 135.1077 \\ 198.6002 & 201.4158 & 318.9086 \\ 422.0233 & 515.3749 & 630.2100 \\ 655.0239 & 802.5953 & 802.8122 \\ 969.5211 & 987.5638 & 1025.2027 \\ 1060.2617 & 1079.8773 & 1130.0000 \\ 1179.5263 & 1277.8310 & 1351.4436 \\ 1390.9955 & 1416.5589 & 1426.3272 \\ 1463.5177 & 1476.6316 & 1485.7883 \\ 1491.1673 & 1501.1352 & 1615.8398 \\ 2995.8131 & 3008.6598 & 3028.6257 \\ 3032.6949 & 3040.4606 & 3104.7589 \\ 3110.9322 & 3124.9388 & 3152.6182\end{array}$




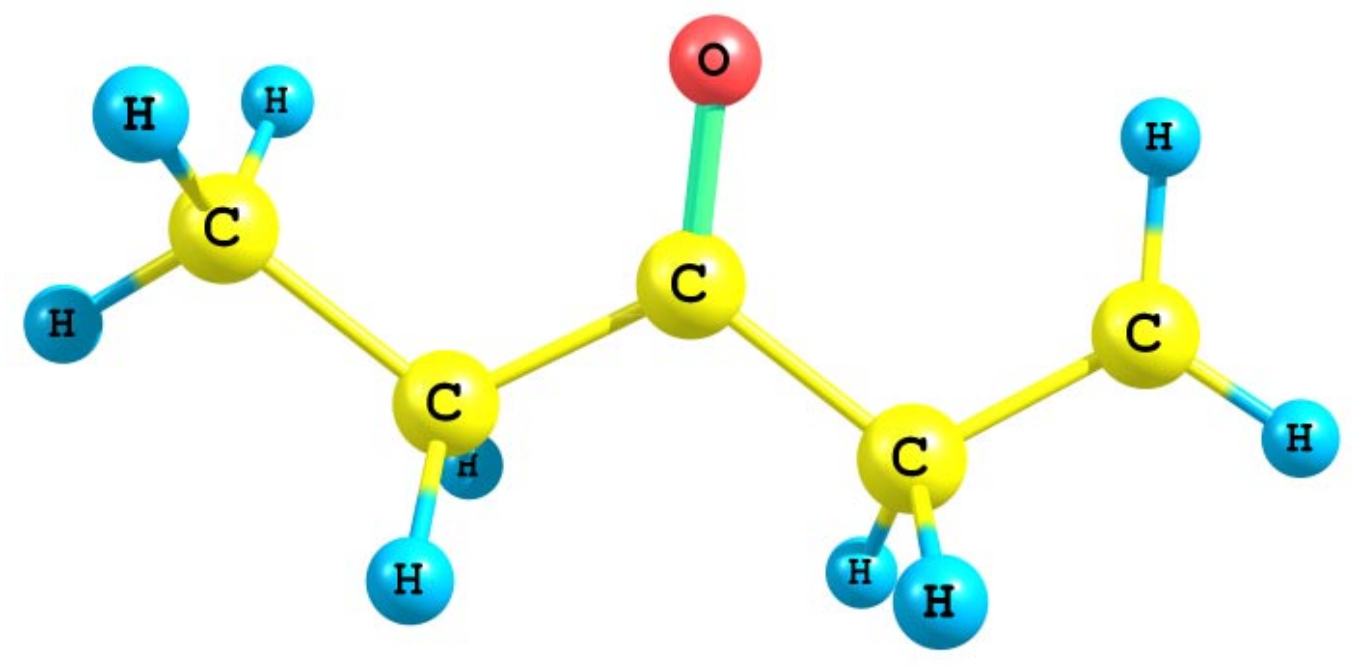

$\begin{array}{rrrr}6 & 1.361633000 & -0.698264000 & 0.097320000 \\ 6 & 0.057439000 & 0.095552000 & 0.000474000 \\ 8 & 0.041947000 & 1.304495000 & 0.007012000 \\ 6 & -1.220037000 & -0.728455000 & -0.097069000 \\ 1 & 1.325110000 & -1.530732000 & -0.621108000 \\ 1 & 1.339517000 & -1.202729000 & 1.080905000 \\ 1 & -1.176071000 & -1.525999000 & 0.654683000 \\ 1 & -1.192290000 & -1.246481000 & -1.065246000 \\ 6 & -2.497368000 & 0.095834000 & 0.038010000 \\ 1 & -2.530717000 & 0.885275000 & -0.714342000 \\ 1 & -2.550532000 & 0.577961000 & 1.016519000 \\ 1 & -3.380213000 & -0.536558000 & -0.081347000 \\ 6 & 2.590109000 & 0.118918000 & -0.061701000 \\ 1 & 3.561000000 & -0.355436000 & -0.115575000 \\ 1 & 2.517967000 & 1.197232000 & -0.072781000\end{array}$

Vibrational frequencies $\left(\mathrm{cm}^{-1}\right)$ :

$\begin{array}{clc}52.4056 & 59.9590 & 183.0194 \\ 199.3619 & 207.5048 & 320.3059 \\ 407.8610 & 431.5000 & 483.2175 \\ 620.5326 & 726.2281 & 772.8908 \\ 871.8168 & 975.6885 & 998.9606 \\ 1033.0921 & 1062.4605 & 1118.9473 \\ 1133.1336 & 1184.7026 & 1287.2622 \\ 1347.0475 & 1380.4782 & 1416.9909 \\ 1425.8287 & 1438.4388 & 1457.0166 \\ 1494.8527 & 1503.3173 & 1797.7575 \\ 2922.8755 & 2984.7932 & 3008.9603 \\ 3036.0025 & 3042.5430 & 3104.9854 \\ 3116.1515 & 3154.4602 & 3267.3588\end{array}$

